\title{
Cannibalism of Atlantic cod Gadus morhua larvae and juveniles on first-week larvae
}

\author{
Velmurugu Puvanendran ${ }^{1,2, *}$, Benjamin J. Laurel ${ }^{1,3}{ }^{\text {, Joseph A. Brown }}{ }^{1, \dagger}$ \\ ${ }^{1}$ Ocean Sciences Centre, Memorial University of Newfoundland, St. John's, Newfoundland A1C 5S7, Canada \\ ${ }^{2}$ Present address: Nofima, 9-13 Muninbakken, 9291 Tromsø, Norway \\ ${ }^{3}$ Present address: Fisheries Behavioral Ecology Program, Alaska Fisheries Science Center, NOAA Fisheries, \\ Hatfield Marine Science Center, Newport, Oregon 97365, USA
}

\begin{abstract}
Cannibalism in Atlantic cod Gadus morhua is widespread under both field and culture conditions, but no studies have been conducted on the behavioural ontogeny of cannibalism in this species. We carried out an experiment to investigate the onset and ontogenetic changes in cannibalistic behaviour of Atlantic cod during early developmental stages. Cod larvae were separated into 4 size classes $(6,9,12$ and $15 \mathrm{~mm})$ to monitor cannibalistic activity on first-week $(\sim 4 \mathrm{~mm})$ conspecific larvae. Five cannibalistic behaviours (fixation, aggression, fin nipping, attacking and engulfing) were monitored when the predator was introduced to the observation chamber. Cannibalistic attacks initially appeared in $9 \mathrm{~mm}$ predators, although $6 \mathrm{~mm}$ larvae showed prey interest and engaged in fin nipping behaviour. The 9 and $12 \mathrm{~mm}$ larvae engaged in similar rates of cannibalistic activity, while $15 \mathrm{~mm}$ fish demonstrated a significant increase. These behavioural changes appear to coincide with the morphological and physiological changes associated with juvenile metamorphosis, namely fin ray, vertebrae and stomach development. More importantly, our observations indicate that cannibalism reduces survival of conspecifics at earlier developmental stages than indicated by diet analyses alone.
\end{abstract}

KEY WORDS: Conspecifics · Cannibalistic behaviour · Atlantic cod · Intra-cohort

\section{INTRODUCTION}

Cannibalism is prevalent in most animal groups, including fishes, and is regarded as one of the most important events regulating population dynamics (Fox 1975). Cannibalism is a size-selective form of predation, and therefore has consequences on both the abundance and size structure of the entire population. Both inter-cohort (reported as a common occurrence) and intra-cohort cannibalism (less commonly reported) affect year class strength in various fish species (Smith \& Reay 1991). While the predator to prey size ratio is likely the most important factor governing rates of cannibalism, other additional factors may also be important, such as food availability, fish density, size variation, kinship and/or genetics (Smith \& Reay 1991).

Atlantic cod Gadus morhua has been a commercially important fish species in the North Atlantic for centuries, in capture fisheries and more recently as an aquaculture species. Although most of the basic culture conditions are established, problems in certain areas still exist, including larval and juvenile mortalities due to cannibalism (Brown et al. 2003, Rosenlund \& Halldórsson 2007). Cannibalism in Atlantic cod is a common occurrence in both wild fish stocks and in aquaculture, and the losses can be devastating under culture conditions if it is not managed properly (Folkvord 1991, Bogstad et al. 1994). Batch spawning over the course of 2 to 3 mo can lead to high within-year size 
variation, with first feeding larvae and early juveniles often co-occurring both spatially and temporally (Folkvord 1997). Due to this, cannibalism in Atlantic cod has received considerable attention in field and aquaculture studies and is assumed to significantly affect recruitment to the cod fishery as well as contribute to high economic losses in the cod aquaculture industry (Bogstad et al. 1994, Blom \& Folkvord 1997). Surprisingly, no incidences of cannibalism have been reported in larval stages (Ellertsen et al. 1984, Perry \& Neilson 1988). This may be because most cannibalism studies on cod have concentrated on the morphological constraints and causes of cannibalism (Folkvord 1991, Bogstad et al. 1994) and are largely based on stomach content analysis and mortality rates (Folkvord \& Otterå 1993, Blom \& Folkvord 1997). Furthermore, smaller conspecific prey tend to be digested faster and may not have been identified in stomach content analyses (Folkvord 1993).

To date, no studies have undertaken a behavioural approach to the phenomenon, thus leaving many of the underlying dynamics associated with cannibalistic activity in cod unknown. A better understanding of the underlying behavioural mechanism of cannibalism, along with existing information on morphological constraints, would be helpful in managing Atlantic cod both under field and culture conditions. The purpose of the present study was to directly observe cannibalistic behaviour of cod to: (1) determine the onset of predation on first-week cod larvae from conspecific fish and (2) understand how cannibalism and associated behaviours may change throughout development.

\section{MATERIALS AND METHODS}

Eggs of Gadus morhua were collected from a spontaneously spawning group of captive broodstock kept at the Ocean Sciences Center, Memorial University of Newfoundland, Canada. Larval cod acting as predators were reared from 2 egg batches separated by $14 \mathrm{~d}$ to ensure availability of 4 separate predator size classes; $6,9,12$, and $15 \mathrm{~mm}$. For the first-week posthatch larvae, eggs were collected from the same group of broodstock when the older larvae were 5 wk posthatch. Eggs were incubated in a flow through system using $250 \mathrm{l}$ conical silos, with a water exchange rate of $51 \mathrm{~min}^{-1}$ at a temperature between 5 and $6^{\circ} \mathrm{C}$. Aeration kept the eggs evenly distributed in the water column. Dead eggs were removed from the tank on a daily basis.

After $100 \%$ hatch, larvae were transferred to $250 \mathrm{l}$ conical silos at a larval density of 50 larvae $\mathrm{l}^{-1}$. All larval batches used for predators and prey in the experiment were reared under similar conditions. Larval rearing temperature was maintained between 8 and $12^{\circ} \mathrm{C}$ throughout the experimental period. Water exchange was initially $11 \mathrm{~min}^{-1}$ and gradually increased to $51 \mathrm{~min}^{-1}$ towards the end of the rearing period. Larvae were fed enriched rotifers (Super Selco, INVE Aquaculture) from 2 to $40 \mathrm{~d}$ post-hatch (dph) and enriched Artemia from 35 to $55 \mathrm{dph}$. Larvae were reared under continuous light $(24 \mathrm{~h})$ at a light intensity of 2000 lux (see Brown et al. 2003).

Predators were removed from their rearing tanks, measured to the nearest $0.25 \mathrm{~mm}$ on a delineated petri dish, and withheld from food for $24 \mathrm{~h}$ prior to observation trials. Then, 3 predators of the same size class along with 60 first-week cod larvae (prey) were placed into 21 glass bowls submersed in a water bath maintained at rearing temperature. Behavioural observations of predator and prey were taken for a $15 \mathrm{~min}$ period. Behavioural observations on 9 replicates of 4 predator size classes were conducted over a period of $6 \mathrm{~d}$ for a total of 36 trials.

Prey sizes averaged ( \pm SD) $4.3 \pm 0.3 \mathrm{~mm}$ (1 to $6 \mathrm{dph}$ ) during the $6 \mathrm{~d}$ period of observations, as measured by a sub-sample of 20 larvae on Days 1, 3 and 5 of the observation trials. To account for prey growth over the course of the experiment and to reduce the bias, 6 and $12 \mathrm{~mm}$ predators were observed on Days 1, 3 and 5, while 9 and $15 \mathrm{~mm}$ predators were observed on Days 2, 4 and 6 . None of the predators or prey was used again during the experiment.

Observations were made by 1 observer sitting behind a curtain to reduce disturbances by any movements of the observer. The observer sat $50 \mathrm{~cm}$ away to permit a full-field view of the tank and larvae. Overall, 5 types of behaviour were observed in each $15 \mathrm{~min}$ trial period (Table 1), and the frequency of each behaviour was recorded using an event counter. Attack likelihood and prey capture ability were calculated as:

$$
\begin{aligned}
& \text { Attack likelihood }=\text { attacking } / \text { fixation } \\
& \text { Capture success }=\text { engulfing } / \text { attacking }
\end{aligned}
$$

Table 1. Gadus morhua. Definitions of the 5 observed canni-

\begin{tabular}{|c|c|}
\hline Behaviour & Description \\
\hline Fixation & $\begin{array}{l}\text { Interest shown by the predator on a prey } \\
\text { item, often characterized by a ' } C \text { ' posture }\end{array}$ \\
\hline Aggression & $\begin{array}{l}\text { Short chase of the prey item after fixation, } \\
\text { which may or may not result in fin nipping }\end{array}$ \\
\hline Fin nipping & $\begin{array}{l}\text { Non-fatal bite on a fish prey, which may or } \\
\text { may not proceed to an attack }\end{array}$ \\
\hline Attacking & $\begin{array}{l}\text { Attempt to strike and engulf a prey item } \\
\text { which could result in a miss or engulfing }\end{array}$ \\
\hline Engulfing & $\begin{array}{l}\text { Successful cannibalistic attack in which } \\
\text { the prey is consumed }\end{array}$ \\
\hline
\end{tabular}
balistic behaviour types of larval and pre-juvenile Atlantic cod 
Changes in behaviour with predator size were analysed using ANOVA. Subsequent comparisons between size classes were conducted using Scheffé post hoc tests. If the assumptions of normality could not be met, data were randomized following procedures outlined by Manly (1991) and Adams \& Anthony (1996). Significance was set at 0.05 .

\section{RESULTS}

Size of Atlantic cod Gadus morhua had a significant effect on cannibalistic behaviour (Table 2). All predator sizes performed fixation, aggression and fin nipping behaviour, but the frequencies increased with predator size (Fig. 1). The $6 \mathrm{~mm}$ predator showed an interest (fixation) in first-week larvae and performed occasional fin nipping, but did not attack and engulf any larvae during the course of the experiment. The $9 \mathrm{~mm}$ predators were able to attack and consume firstweek larvae, but were also observed fin nipping larvae they did not consume. The $15 \mathrm{~mm}$ predators did not show much interest in fin nipping, and instead showed

Table 2. ANOVA results for effect of size on cannibalistic behaviour

\begin{tabular}{|lrc|}
\hline Behavior & $F_{3,35}$ & $\mathrm{p}$ \\
\hline Fixation & 53.57 & $<0.001$ \\
Aggression & 30.74 & $<0.001$ \\
Fin nipping & 5.71 & $<0.003$ \\
Attacking & 45.49 & $<0.001$ \\
Engulfing & 52.84 & $<0.001$ \\
\hline
\end{tabular}

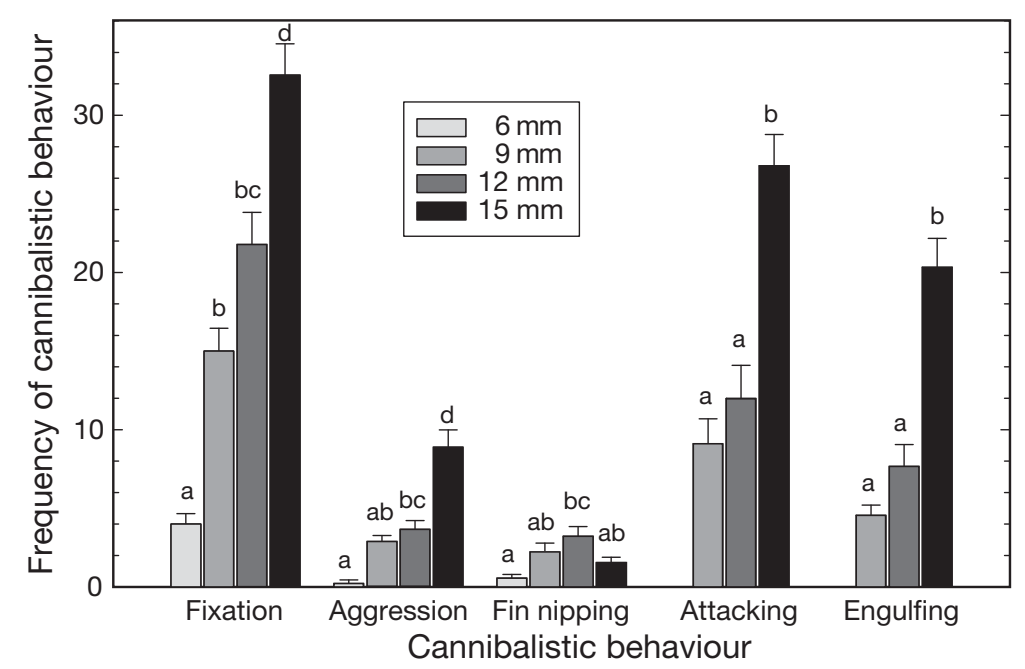

Fig. 1. Gadus morhua. Frequency of cannibalistic behaviour (mean $\pm \mathrm{SD}$ ) of 6 to $15 \mathrm{~mm}$ Atlantic cod on the first-week conspecific larvae during a $15 \mathrm{~min}$ observation period. Different letters within a behavioural response indicate significant difference $(\alpha=0.05)$

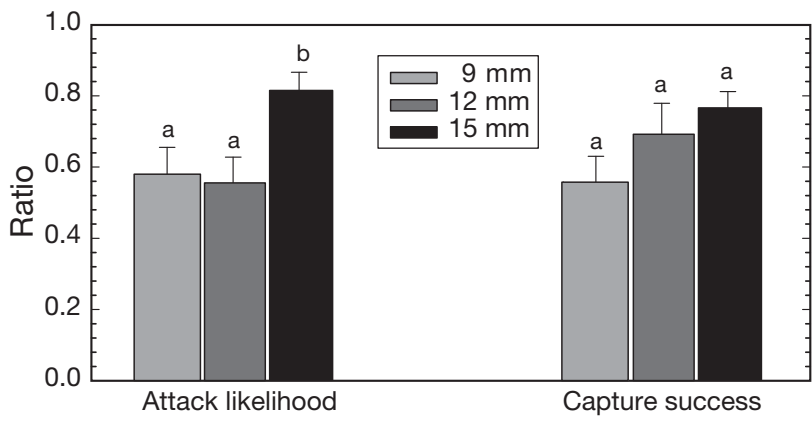

Fig. 2. Gadus morhua. Mean attack likelihood and capture success $( \pm \mathrm{SD})$ of 9 to $15 \mathrm{~mm}$ Atlantic cod on the first-week conspecific larvae. Different letters within a behavioural response indicate significant difference $(\alpha=0.05)$

higher rates of attacking and engulfing than the smaller predator size classes. Among the 3 larger predators, the number of incidents of attacking and engulfing increased with increasing size (Fig. 1). While no significant differences were found in any of the observed behaviours between 9 and $12 \mathrm{~mm}$ predators, $15 \mathrm{~mm}$ predators showed higher frequencies of fixation, aggression, attacking and engulfing (Fig. 1).

Fixation did not always end in an attack, nor did an attack always lead to the consumption of prey (Fig. 1). Attack likelihood was similar between 9 and $12 \mathrm{~mm}$ predators $(\mathrm{p}=0.064)$, but $15 \mathrm{~mm}$ predators had higher attack likelihood ( $p=0.033$ ) (Fig. 2). Capture success consistently increased with increasing predator body size. The $15 \mathrm{~mm}$ predator represented the greatest threat in terms of absolute number of attacks and engulfments to $1 \mathrm{wk}$ old cod larvae; however, 9 and $12 \mathrm{~mm}$ predators also demonstrated similar threats when considering the capture success (Fig. 2).

\section{DISCUSSION}

To date, studies on cannibalism in Atlantic cod have been restricted to larger-sized individuals than those examined in our study (Folkvord 1993, Folkvord \& Otterå 1993, Blom \& Folkvord 1997, Uzars \& Plikshs 2000). While most field studies on cannibalism have analysed the gut contents of cod > $350 \mathrm{~mm}$ (Uzars \& Plikshs 2000), the smallest cod studied were about $21 \mathrm{~mm}$ in a laboratory study (Folkvord 1993) and about $130 \mathrm{~mm}$ in a semi-intensive system (Blom \& Folkvord 1997) (Fig. 3).

Few studies have so far investigated the ontogeny of cannibalistic behaviour in fishes (Loadman et al. 1986, Sakakura \& Tsuka- 


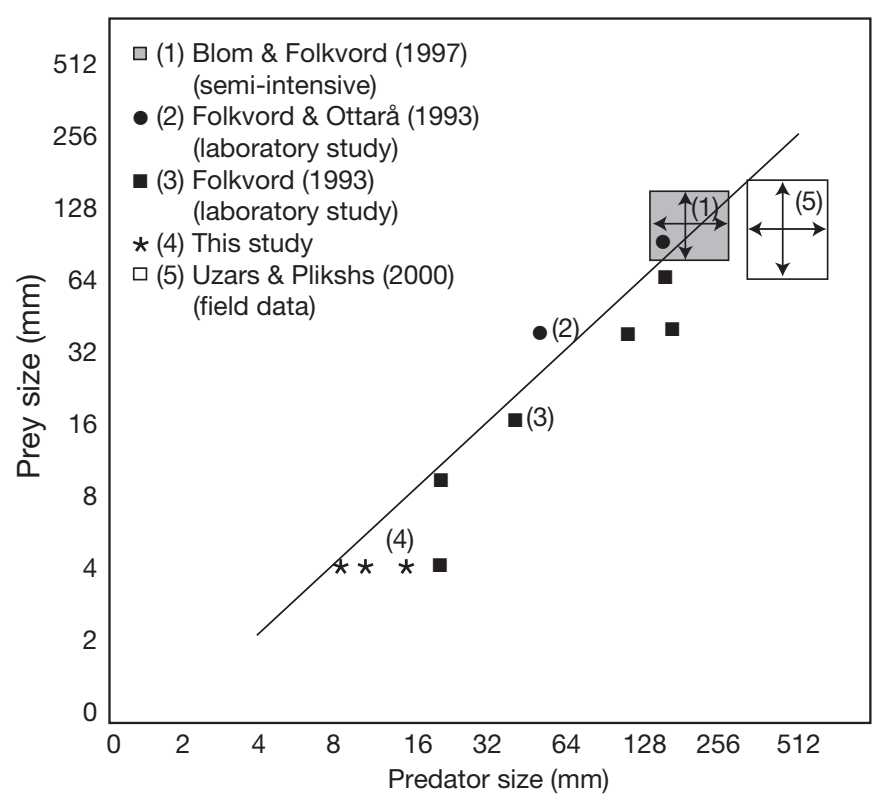

Fig. 3. Gadus morhua. Prey-predator length relationships in present and previous cod cannibalism studies. The line represents the 1:2 ratio of prey and predator size

moto 1996, Baras 1999, Baras \& Jobling 2002). Of the studies that have incorporated behavioural observations, most were designed to characterize the mechanics of cannibalism (e.g. attack orientation) rather than its onset (Loadman et al. 1986, Baras 1999, Baras \& Jobling 2002) and examined larger juveniles than reported in our study (e.g. Baras 1999). Cannibalism studies on larval and early juveniles of cod received less attention, likely because the available field information rules out intra-cohort cannibalism (Ellertsen et al. 1984, Perry \& Neilson 1988). However, studies of semi-intensive systems, such as large marine ponds, suggest intra-cohort cannibalism in cod (Folkvord et al. 1994, Blom \& Folkvord 1997). Sakakura \& Tsukamoto (1996) showed that young yellowtail Seriola quinqueradiata exhibit strong cannibalistic behaviour at $23 \mathrm{dph}$ (10 mm total length), and they attributed this elevated aggression to greater size variation within the cohorts. In the present study, the frequencies of aggressive and cannibalistic behaviours increased as the size differences between prey and predator increased. The age difference between prey and both the larger and smaller predators in our study was 48 and 34 d, respectively, and Folkvord et al. (1994) showed that cannibalism could be a major cause of mortality when the age difference among cohorts is $>10$ to $20 \mathrm{~d}$ and the food supply is limited.

Cannibalistic behaviour of larger conspecifics on first-week cod larvae appears to develop sometime between 6 and $9 \mathrm{~mm}$. Although $6 \mathrm{~mm}$ larvae showed some interest (fixating) on smaller first-week larvae, they did not fully attack (but did nip the fins) the larvae despite being starved $24 \mathrm{~h}$ prior to the onset of the experiment. This fin nipping aggressive behaviour has been seen as the precursor of cannibalism in other fish species, as could also be the case for cod (Sakakura \& Tsukamoto 1996). Cod larvae are gape-limited predators; thus, the relationship between prey body depth and predator mouth gape is a limiting factor (Otterå \& Folkvord 1993, Puvanendran et al. 2004). Using an empirical model, Otterå \& Folkvord (1993) suggested that a $6 \mathrm{~mm}$ larva has the ability to cannibalize a $4.5 \mathrm{~mm}$ larva, as the body depth of the prey and mouth gape of the predator would be similar. But they have acknowledged that it is unlikely that cod, as a gapelimited predator, would consume a prey of similar body height to its own mouth gape and suggested that larger conspecifics would comfortably cannibalize a prey having $75 \%$ of the body depth of its mouth gape. Thus, failure to attack the $4.3 \mathrm{~mm}$ prey by the $6 \mathrm{~mm}$ predator in our experiment could be due to the morphological constraint of having a smaller mouth gape (0.69 $\mathrm{mm})$ compared to the body depth $(0.72 \mathrm{~mm}$ with yolk sac) of the $4.3 \mathrm{~mm}$ cod larvae (Folkvord 1997, Puvanendran et al. 2004, V. Puvanendran unpubl. data). Studies on the relationship between prey body depth to predator mouth gape ratios and cannibalism or piscivory are limited, compared to body-length relationships. However, few studies show a tight correlation between prey body depth to predator mouth gape ratios or prey length to predator length ratios (Nilsson \& Brönmark 1999, Juanes 2003). The fixation period may be part of the decision making process in which the predator determines whether it can successfully ingest its prey. Other behavioural studies involving Atlantic cod larvae reported 'passes' (Puvanendran et al. 2002) or 'aborted attacks' (Hunt von Herbing \& Gallager 2000) in which the larvae terminate pursuit of a prey item, possibly because another suitable prey item enters the field-of-view and/or the prey item is determined to be too large to handle.

Fin nipping is an aggressive behaviour that could have some competitive importance, yet the significance of this behaviour is not clear, as it varies depending on the species. In salmonids, fin nipping has been interpreted as social behaviour in escalated conflicts, with the severity of fin damage sustained by different individuals possibly reflecting their position in a social hierarchy (Abbott \& Dill 1985, Moutou et al. 1998). Although fin nipping in our study increased in predators from 6 to $12 \mathrm{~mm}$, it appears that fin nipping is not an important cannibalistic behaviour of larval and juvenile cod of any of the sizes tested. Moreover, fin nipping frequency was reduced in $15 \mathrm{~mm}$ predators to the level found in $6 \mathrm{~mm}$ predators, possibly reflecting the improved predatory skills of larger predators. 
Similar fin nipping incidences were reported in winter flounder and Atlantic cod juveniles (55 to $450 \mathrm{~g}$ ), whereby smaller juveniles were subjected to more fin nipping compared to larger juveniles, but no direct mortalities were related to this behaviour (Fairchild \& Howell 2001, Hatlen et al. 2006). Fin nipping may not be beneficial for the predator in terms of energy gains, but it could have serious negative impacts on the prey, as the damaged fin may impair their swimming, foraging and predator escape capabilities. These weakened and stressed individuals may eventually benefit the predator, because they may become easier to catch and consume (Sogard \& Olla 1994). Studies on walleye Stizostedion vitreum (Loadman et al. 1986) and walleye pollock Theragra chalcogramma (Sogard \& Olla 1994) showed that 19 and $36 \%$ of the fish that were attacked died within $24 \mathrm{~h}$, respectively. In our study, the fish were not observed beyond the observation period; thus, the fate of these fin-nipped fish is unknown.

Our results showed that the cannibalistic acts of attacking and engulfing $4.3 \mathrm{~mm}$ first-week larvae first developed in $9 \mathrm{~mm}$ predators. Folkvord et al. (1994) reported that in situations where cohorts of Atlantic cod larvae separated by $20 \mathrm{~d}$ in age were reared together, mortality rates in the younger cohort were higher when copepod densities were low. At that time, the cohorts had standard lengths of 9 to $15 \mathrm{~mm}$ (older) and 5 to $7 \mathrm{~mm}$ (younger). They suggested that the early juveniles from older cohorts had the ability (having the length ratio of $1.3: 1$ to $3: 1$ ) and motivation (low copepod density) to cannibalize the younger cohort. Folkvord et al. (1994) therefore concluded that cannibalism was the most probable explanation for the high rates of mortality, rather than food availability or other unexplained environmental factors. Our results support their prediction, which showed that the attack frequencies increased significantly as the predator size increased from 12 to $15 \mathrm{~mm}$. As the larvae grew, the fixation period was more frequently followed by an attack on a prey item, but such attacks commonly missed the prey. The failure to capture prey could be a result of the enhanced escape behaviour of the prey. Similar observations of limited success are reported in other behavioural investigations involving marine finfish foraging on zooplankton (Hunt von Herbing \& Gallager 2000, Puvanendran et al. 2002). However, absolute number of attacks and engulfments increased with increasing predator size, a result which agrees with observations from other studies based on morphometrics that cannibalistic mortality increases as size variation increases in the cohort (Folkvord 1997).

Not surprisingly, $15 \mathrm{~mm}$ fish represented the greatest cannibalistic threat to first-week larvae in terms of incidents of attacking and engulfing. There appears to be a significant ontogenetic shift in behaviour between 12 and $15 \mathrm{~mm}$, which would correspond with the morphological and physiological changes associated with juvenile metamorphosis (Pedersen \& Falk-Petersen 1992). Between 11 and $15 \mathrm{~mm}$ cod larvae develop vertebrae and fin rays that contribute to increased predatory skills through higher sustained and burst swimming speeds and improved manoeuvring (Pedersen \& Falk-Petersen 1992). Pedersen \& Falk-Petersen (1992) found that the stomach and the pyloric caeca of Atlantic cod start to develop at $15 \mathrm{~mm}$ and that the capacity of the stomach to hold more food begins to increase significantly at $20 \mathrm{~mm}$. This could have enabled the $15 \mathrm{~mm}$ cod to consume significantly more prey than the smaller predators used in our study.

Our study was conducted in a small container, and the contact rate could have been higher than in natural environments; thus, comparison of the results from our study with in situ conditions should be done cautiously. With the difficulties involved in the simulation natural environments of fish larvae in mind, results from these studies nonetheless provide greater depth to our understanding of larval behaviour (Munk 1995, Laurel et al. 2001, Puvanendran et al. 2002, 2004).

In conclusion, our study demonstrated that aggressive behaviour develops as early as in $6 \mathrm{~mm}$ Atlantic cod larvae and that it increases as relative predator to prey size increases. The cannibalistic acts of attack and capture start as early as in $9 \mathrm{~mm}$ larvae. Previous cannibalistic studies based on gut contents and mortality data have not indicated that cannibalistic behaviour and acts begin this early in larval cod, despite providing insight into the morphological constraints of cannibalism. Although, our study demonstrated possible intra-cohort cannibalism in Atlantic cod using behavioural observation alone, further studies of cannibalism between different size classes in combination with behavioural observations, gut content and mortality data are warranted to enhance our knowledge of ontogeny of cannibalism in Atlantic cod.

Acknowledgements. We thank Dr. Vytensis Gotceitas for his suggestions in the early stages of this study. We also thank Drs. Linda Hansen and Chris Noble for their critical comments. This study was supported by the Natural Sciences and Engineering Research Council of Canada (NSERC) funding awarded to J.A.B. The research protocol was approved by the Memorial University's Committee on Animal Welfare, in accordance with the guidelines provided by the Canadian Council on Animal Care.

\section{LITERATURE CITED}

Abbott JC, Dill LM (1985) Patterns of aggressive attack in juvenile steelhead trout (Salmo gairdneri). Can J Fish Aquat Sci 42:1702-1706

Adams DC, Anthony CD (1996) Using randomization techni- 
ques to analyse behavioural data. Anim Behav 51:733-738

Baras E (1999) Sibling cannibalism among juvenile vundu under controlled conditions. I. Cannibalistic behaviour, prey selection and prey size selectivity. J Fish Biol 54: 82-105

Baras E, Jobling M (2002) Dynamics of intracohort cannibalism in cultured fish. Aquacult Res 33:461-479

Blom G, Folkvord A (1997) A snapshot of cannibalism in 0-group Atlantic cod (Gadus morhua) in a marine pond. J Appl Ichthyol 13:177-181

Bogstad B, Lilly GR, Mehl S, Palsson OK, Stefansson G (1994) Cannibalism and year-class strength in Atlantic cod (Gadus morhua L.) in arcto-boreal ecosystems (Barents Sea, Iceland, and eastern Newfoundland). ICES Mar Sci Symp 198:576-599

Brown JA, Minkoff G, Puvanendran V (2003) Larviculture of Atlantic cod (Gadus morhua): progress, protocol and problems. Aquaculture 227:357-372

Ellertsen B, Fossum P, Solemdal P, Tilseth S (1984) A case study on the distribution of cod larvae and availability of prey organisms in relation to physical processes in Lofoten. In: Dahl E, Danielsen E, Moksness E, Solemdahl P (eds) The propagation of cod Gadus morhua L. Institute of Marine Research, Bergen, p 453-477

Fairchild E, Howell H (2001) Optimal stocking density for juvenile winter flounder Pseudopleuronectes americanus. J World Aquacult Soc 32:300-308

Folkvord A (1991) Growth, survival and cannibalism of cod juveniles (Gadus morhua): effects of feed type, starvation and fish size. Aquaculture 97:41-59

Folkvord A (1993) Prey recognition in stomachs of cannibalistic juvenile cod (Gadus morhua L.). Sarsia 78:97-100

Folkvord A (1997) Ontogeny of cannibalism in larval and juvenile fishes with special emphasis on Atlantic cod. In: Chambers RC, Trippel EA (eds) Early life history and recruitment in fish populations. Chapman \& Hall, London, p 251-278

Folkvord A, Otterå H (1993) Effects of initial size distribution, day length and feeding frequency on growth, survival and cannibalism in juvenile Atlantic cod (Gadus morhua L.). Aquaculture 114:243-260

Folkvord A, Øiestad V, Kvenseth PG (1994) Growth patterns of three cohorts of Atlantic cod larvae (Gadus morhua L.) studied in a macrocosm. ICES J Mar Sci 51:325-336

Fox LR (1975) Cannibalism in natural populations. Annu Rev Ecol Syst 6:87-106

Hatlen B, Grisdale-Hellanda B, Helland SJ (2006) Growth variation and fin damage in Atlantic cod (Gadus morhua L.) fed at graded levels of feed restriction. Aquaculture 261:1212-1221

Hunt von Herbing I, Gallager SM (2000) Foraging behavior in early Atlantic cod larvae (Gadus morhua) feeding on a protozoan (Balanion sp.) and a copepod nauplius (Pseudodiaptomus sp.). Mar Biol 136:591-602

Editorial responsibility: Paul Sammarco, Chauvin, Louisiana, USA
Juanes F (2003) The allometry of cannibalism in piscivorous fishes. Can J Fish Aquat Sci 60:594-602

Laurel BJ, Brown JA, Anderson R (2001) Behaviour, growth and survival of redfish (Sebastes sp.) larvae in relation to prey availability. J Fish Biol 59:884-901

Loadman NL, Moodie GEE, Mathias JA (1986) Significance of cannibalism in larval walleye (Stizostedion vitreum). Can J Fish Aquat Sci 43:613-618

Manly BFJ (1991) Randomization and Monte Carlo methods in biology. Chapman \& Hall, London

Moutou KA, McCarthy ID, Houlihan DF (1998) The effect of ration level and social rank on the development of fin damage in juvenile rainbow trout. J Fish Biol 52: $756-770$

Munk P (1995) Foraging behaviour of larval cod (Gadus morhua) influenced by prey density and hunger. Mar Biol 122:205-212

> Nilsson PA, Brönmark C (1999) Foraging among cannibals and kleptoparasites: effects of prey size on pike behavior. Behav Ecol 10:557-566

Otterå H, Folkvord A (1993) Allometric growth in juvenile cod (Gadus morhua L.) and possible effects on cannibalism. J Fish Biol 43:643-645

Pedersen T, Falk-Petersen IB (1992) Morphological changes during metamorphosis in cod (Gadus morhua L.) with particular reference to the development of the stomach and pyloric cecae. J Fish Biol 41:449-461

Perry RI, Neilson JD (1988) Vertical distributions and trophic interactions of age-0 Atlantic cod and haddock in mixed and stratified waters of Georges Bank. Mar Ecol Prog Ser 49:199-214

> Puvanendran V, Leader LL, Brown JA (2002) Effect of prey concentration on the development of foraging behaviour in larval Atlantic cod from hatching to metamorphosis. Can J Zool 80:689-699

> Puvanendran V, Salies K, Laurel B, Brown JA (2004) Size dependent foraging of larval Atlantic cod (Gadus morhua). Can J Zool 82:1380-1389

> Rosenlund G, Halldórsson Ó (2007) Cod juvenile production: research and commercial developments. Aquaculture 268: 188-194

Sakakura Y, Tsukamoto K (1996) Onset and development of cannibalistic behaviour in early life stages of yellowtail. J Fish Biol 48:16-29

Smith C, Reay P (1991) Cannibalism in teleost fish. Rev Fish Biol Fish 1:41-64

Sogard SM, Olla BL (1994) The potential for intracohort cannibalism in age-0 walleye pollock, Theragra chalcogramma, as determined under laboratory conditions. Environ Biol Fishes 39:183-190

Uzars D, Plikshs M (2000) Cod (Gadus morhua L.) cannibalism in the central Baltic: interannual variability and influence of recruit abundance and distribution. ICES J Mar Sci 57:324-329

Submitted: October 4, 2007; Accepted: March 11, 2008 Proofs received from author(s): April 15, 2008 